\title{
Returns to Investment in Higher Education: Is There a Difference between Distance Learning and Traditional Universities in the Fields of Physics, Mathematics, Social Studies, Computer Science and Economics?
}

\author{
George Agiomirgianakis ${ }^{1}$, Theodore Lianos ${ }^{2}$, Nicholas Tsounis ${ }^{3}$ \\ ${ }^{1}$ School of Social Sciences, Hellenic Open University, Patras, Greece \\ ${ }^{2}$ Professor Emeritus, Athens University of Business and Economics, Athens, Greece \\ ${ }^{3}$ Department of International Trade, Technological Institute of Western Macedonia, Adjunct Faculty, Hellenic Open University, \\ Kastoria, Greece \\ Email: gmagios@eap.gr, plianos@aueb.gr, tsounis@kastoria.teikoz.gr
}

How to cite this paper: Agiomirgianakis, G., Lianos, T., \& Tsounis, N. (2018). Returns to Investment in Higher Education: Is There a Difference between Distance Learning and Traditional Universities in the Fields of Physics, Mathematics, Social Studies, Computer Science and Economics? Creative Education, 9, 2920-2938.

https://doi.org/10.4236/ce.2018.916220

Received: October 20, 2018

Accepted: December 25, 2018

Published: December 28, 2018

Copyright $\odot 2018$ by authors and Scientific Research Publishing Inc. This work is licensed under the Creative Commons Attribution International License (CC BY 4.0).

http://creativecommons.org/licenses/by/4.0/

\begin{abstract}
In this paper, we extend the literature on the rate of returns to Investment in Higher Education towards studies in distance learning Universities. In particular, we explore the difference in returns between, on one hand, graduates of a distance learning university (the Hellenic Open University, HOU) and on the other hand, graduates from two traditional universities, in Greece. The data used in the analysis is collected with field research from graduates of Physics, Mathematics, Social Studies, Computer Science and Economics. Our findings show that the rate of return to investment in education for $\mathrm{HOU}$ graduates is about four times higher than that of the graduates of the two traditional Universities, for the first degree graduates and about double the rate for the Master's degree graduates. From policy perspective, our results suggest that a distance learning University may not only be considered as a second chance to education for mature students, often facing time and budget restrictions, but, it may also be seen as a worthwhile investment enabling much higher private returns compared to the alternative route, i.e. following studies in traditional universities. Therefore, distance learning universities may be used by policy authorities as a vehicle to reduce income inequalities and increase social mobility.
\end{abstract}

\section{Keywords}

Economic Policy, Returns to Investment in Education, Distance Learning, 
Higher Education, Mincer Equation, Physics Education, Mathematics Education, Economic Education, Computer Education, Social Studies Education

\section{Introduction}

The theory of human capital was introduced in the general economic theory by the work of three scholars: Mincer (1958), Schultz (1961) and Becker (1964). Since then the human capital theory and empirical studies have experienced a phenomenal growth. Human capital is now a major element of analysis in studies relating to the remuneration of workers, distribution of income, the likelihood of unemployment for various groups of people, migration between regions and between countries, social mobility between generations, technology and economic development. In the literature section below, we present and discuss the results from several empirical studies examining the returns to investment in higher education worldwide and in Greece.

The purpose of this paper is first, to provide an estimation of the returns to investment in education, i.e. the effects of a university degree on wages in Greece and second, to provide an estimation of the difference (if any) between the education returns of the Hellenic Open University (HOU) graduates and the traditional universities graduates. The data used was extracted from 2112 questionnaires that were collected with field research in $2014^{1}$ from graduates of Physics, Mathematics, Social Studies, Computer Science and Economics.

The remainder of the paper is organized as follows. Section 2 presents a brief review of the literature regarding previous findings on returns to investment in education, with emphasis in Greece. Section 3 presents our model of a modified Mincer equation for measuring education returns, the specification of variables used, and we provide a description of the data and present the estimating methodology. Section 4 discusses the estimation results from our Mincer type model and presents the returns to investment in education in Greece for the distance learning University and traditional universities, as well as, the test of the difference between them. Finally, Section 5 contains concluding remarks and states the policy implications of our findings.

\section{Literature Review}

There have been several studies estimating the rate of return to higher education (see e.g. D’Aguiar, \& Harrison (2016), Naylor et al. (2015); Oreopoulos et al. (2013); Psacharopoulos (2012), Harmon (2011) and Heinrich \& Hildebrand (2005) for some excellent surveys in different time periods). For Greece there have been several studies beginning as early as 1965 . The first study was done by Leibestein in 1965 and found a "low" rate of return. Psacharopoulos (1982), and

${ }^{1}$ Please see the "Data description" section below for details. 
Lambropoulos and Psacharopoulos (1992) using the same data as Leibenstein (1967) and a specially designed questionnaire of the Statistical Service of Greece (NSSG) have found a rate of return of $15 \%$ for $1960,14 \%$ for $1964,15.1 \%$ for $1975,10.5 \%$ for $1977,13.6 \%$ for 1981 and $10.2 \%$ for 1985 .

Ten years later, Patrinos (1995) using data from the Wage Survey of the National Statistical Service (NSSG) for the year 1977 and Kanellopoulos (1997) with data from the Household Survey of NSSG for year 1987-8, have found very similar rates of return, namely $5.6 \%$ and $5.4 \%$, respectively.

Using more recent data of the 1993 Household Survey of NSSG, Magoula and Psacharopoulos (1999) estimated the rate of return for 1993 to be $6.3 \%$. Two years later Tsakloglou and Cholezas (2001) estimated the rate of return for men and women using the Household Surveys for the years 1974, 1988 and 1995 and found them to be $9.3 \%, 6.2 \%$ and $8.7 \%$ for men for the respective years and $11.9 \%, 8.0 \%$ and $10.4 \%$ for women. Tsakloglou and Cholezas re-estimated the rate of return adjusting for the periods of unemployment of each individual but the differences are negligible. In a more recent work Prodromidis and Prodromidis (2008) using the same source of data have found estimates of rate of return for men and women for the years 1988, 1994 and 1998 as follows 3.9\%, 6.3\% and $7.6 \%$ for men for the respective years and $8.1 \%, 6.2 \%$ and $14.1 \%$ for women.

Four recent studies by Mitrakos et al. (2010), by Livanos and Pouliakas (2011), by Kanellopoulos et al. (2013) and by Kanellopoulos and Cholezas (2014) have used the Labor Survey of the NSSG and have estimated rates of return to higher education for more recent years. Mitrakos et al. (2010) have used the Labor Surveys of 2004-2007 to estimate the rate of return of twenty years after graduation for several professions. Their estimates range between $4 \%$ and $10.5 \%$, while it is 9.3\% for a post graduate degree and $7.8 \%$ for a doctorate. Livanos and Pouliakas (2011) have found that the rates of return for 2003 for men and women were $5.9 \%$ and $5.0 \%$ respectively for the first degree, $7.6 \%$ and $19.2 \%$ for a Master's and surprisingly negative for a Ph.D., $-2.0 \%$ for men and $-6.6 \%$ for women. $\mathrm{Mi}$ trakos et al., and Kanellopoulos and Cholezas have estimated and compared rates of return for men and women, for various professions for the periods 2004-2007 and 2010-2012, namely before and after the Greek debt crisis. Their results appear in Table 1.

Several comments can be made regarding the results of the above studies. First, the differences of the rates or return estimated for the same or near years are substantial. For example, the rates of return for 1974 and 1977 are $10.6 \%$ and $10.2 \%$, respectively, and for 1975 it is $15.1 \%$. For 1994 the rate of return is estimated by different authors to be $9.6 \%, 8.7 \%$ and $6.3 \%$. One year later, 1995, the estimates are $5.6 \%$ and $5.4 \%$. For the period $2004-7$ the estimates are 5.3\%, $7.0 \%$ and $7.4 \%$.

Second, despite these differences there is a clear negative trend of the rates return for the entire period. Comparing the results of the above studies for years before and after 1981 it appears that the rate of return has been reduced by approximately fifty percent. This decline is probably related to the high rates of 
Table 1. Rates of return to education for university studies by disciple and level of university studies before and after the sovereign debt crisis.

\begin{tabular}{cccccccccc}
\hline & \multicolumn{3}{c}{ Kanellopoulos et al. (2013) } & \multicolumn{2}{c}{ Kanellopoulos and Cholezas (2014) } \\
\cline { 2 - 8 } Discipline & \multicolumn{2}{c}{ 2004-2007 } & 2010-2012 & 2004-2007 & 2010-2012 \\
\cline { 2 - 8 } & Men & Women & Men & Women & Men & Women & Men & Women \\
\hline Mechanical Engineering & $5.2(5.1)$ & $4.8(6.0)$ & $6.7(6.5)$ & $4.3(10.5)$ & $5.9(6.5)$ & $7.0(13.3)$ & $7.8(9.4)$ & $8.6(14.5)$ \\
Computer science & $5.6(6.7)$ & $6.0(10.6)$ & $4.9(6.8)$ & $6.7(12.9)$ & $8.0(6.0)$ & $8.9(15.7)$ & $7.9(11.3)$ & $7.9(12.5)$ \\
Mathematics and Statistics & $4.9(4.3)$ & $5.6(7.2)$ & $4.5(4.9)$ & $8.2(10.4)$ & $6.4(6.4)$ & $7.6(9.4)$ & $5.2(7.6)$ & $10.5(14.2)$ \\
Medicine & $6.8(6.7)$ & $5.5(8.3)$ & $6.1(8.0)$ & $5.4(16.4)$ & $11.0(10.9)$ & $5.8(7.2)$ & $4.3(5.8)$ & $3.2(8.0)$ \\
Law & $6.7(8.3)$ & $5.1(9.2)$ & $4.8(9.0)$ & $4.6(15.1)$ & $7.8(11.3)$ & $8.4(15.9)$ & $6.4(12.2)$ & $12.8(19.2)$ \\
Economics. Management & $4.7(4.1)$ & $4.6(7.1)$ & $5.5(7.0)$ & $4.0(9.4)$ & $6.2(7.6)$ & $7.6(13.6)$ & $1.0(1.9)$ & $8.7(21.4)$ \\
Social science & $4.0(3.0)$ & $4.4(5.3)$ & $2.1(1.1)$ & $4.1(5.7)$ & $5.8(6.2)$ & $6.6(11.8)$ & $6.7(10.8)$ & $7.7(14.6)$ \\
Postgraduate Master's studies & $7.2(7.5)$ & $7.9(11.9)$ & $7.4(9.6)$ & $5.8(12.8)$ & $6.9(7.3)$ & $10.6(16.6)$ & $10.8(15.1)$ & $10.1(19.0)$ \\
Doctoral Degree. Ph.D & $6.8(6.6)$ & $5.3(7.8)$ & $5.3(7.2)$ & $3.8(10.0)$ & $5.2(6.4)$ & $7.4(11.8)$ & $7.1(10.5)$ & $6.1(12.9)$ \\
\hline
\end{tabular}

Source: Kanellopoulos, Mitrakou, Tsakloglou and Cholezas (2013) and Kanellopoulos and Cholezas (2014). Note: In parenthesis are the rates of return adjusted for unemployment. 


\section{Methodology and Data}

\subsection{The Basic Mincer Equation}

Along the lines suggested by Psacharopoulos and Patrinos (2004), we use the Mincer (1958) Equation for the estimation of the private returns of investment (in schooling years) to education. This equation is popular in the literature measuring the returns to the human capital invested by individuals. It is based on a typical model of investment in human capital where people invest in human capital to maximize the present value of future returns.

The Mincer equation in its basic form is:

$$
\ln W=a_{0}+a_{1} S+a_{2} X+a_{3} X^{2}
$$

where $\ln W$ is the logarithm of wages, $S$ the years of education and $X$ the years of working experience, $\alpha_{1}$ is the rate of return for an additional year of education and equal to the discount interest rate.

This equation, though half a century has passed, is still used in several variations as it describes quite well the data in the real world. The dependent variable, wages, is in logarithm, as opposed to independent variables that are the years of education and working experience. Taking the logarithm of the variables is a technique commonly used in econometric models for convenience or for a better fitting to the data. But in the case of the Mincer equation there is also a theoretical justification, see e.g. Bunzel et al. (2008) for the use of the dependent variable in logarithm within a regression that tries to explain the returns to human capital. As noted by Mincer op.cit,, education has a multiplier effect on human capital which is described by the nonlinear increase in earnings compared with the increase of years of education (since $\alpha_{1}>0$ ). Thus, the percentage change in $W$ (wages) after a change of one unit in the years of education is constant (i.e. $a_{1}=\frac{\partial \ln W}{\partial S}=\frac{\% \Delta W}{\Delta S}$.

Following Psacharopoulos and Patrinos (2004) in using questionnaire data, schooling years are replaced by dummy variables for each level of education i.e. in order to find the different rate of return for the different education levels a dummy variable is used for each level of education in the Mincer equation. Thus, the equation takes the form:

$$
\ln W=b_{0}+b_{1} X+b_{2} X^{2}+a_{1} D_{1}+a_{2} D_{2}+a_{3} D_{3}+a_{4} D_{4}
$$

where the variables $D_{1}, D_{2}, D_{3}$ and $D_{4}$ represent the four levels of education: no education, primary, secondary, and university education, respectively.

From (2) the private rates of return between levels of education are calculated by:

$$
R_{b}=\frac{\hat{\alpha}_{1}}{S_{b}}, R_{s}=\frac{\hat{\alpha}_{2}-\hat{\alpha}_{1}}{S_{s}-S_{b}}, R_{U f}=\frac{\hat{\alpha}_{3}-\hat{\alpha}_{2}}{S_{U f}-S_{s}}, R_{U m}=\frac{\hat{\alpha}_{4}-\hat{\alpha}_{3}}{S_{U m}-S_{U f}}
$$

where $R_{b}$ is the rate of return to basic education, $R_{s}$ the rate of return to secondary education, $R_{U f}$ the rate of return to first degree graduates of University 
education, $R_{U m}$ the rate of return to Master's degree graduates of University education and $S$ the years of schooling for each level of education

\subsection{The Modified Mincer Equation}

Mincer equation was modified to account for other factors that might influence wages (apart from the years of experience). These factors are: sex, family status, current state of the respondent in the labour market, degree mark (secondary level or Bachelor's or Master's), relevance of the job to the degree (mismatching), overqualification, sector of employment, active participation in trade unions, knowledge of a foreign language (English, French, German, other) and computer skills (Word, Excel, PowerPoint, database management, use of Internet, accounting packages, other specialised software).

The modified equation had sixty eight dummies and three continues variables, all extracted from the primary data collected with field research ${ }^{2}$ and is shown in (4) below:

$$
\begin{aligned}
\ln W_{t, i}= & b_{0}+b_{1} X_{t, i}+b_{2} X_{t, i}^{2}+b S_{i i}+\sum_{e=1}^{4} \delta_{e} D O M_{e, i}+\sum_{j=1}^{7} f_{j} S L M_{j, i}+m M_{i} \\
& +\sum_{n=1}^{4} r_{n} \text { MATCH }_{n, i}+\sum_{w=1}^{3} q_{w} O Q_{w, i}+\sum_{s s=1}^{20} s_{s s} S E C_{s s, i}+\text { tuTRUN } \\
& +\sum_{x x=1}^{4} \sum_{f e=1}^{4} f l_{x x, f e} L A N G_{-} x x_{f e, i}+\sum_{x=1}^{7} y_{x} \operatorname{COMP}_{x, i} \\
& +a_{2} D_{2, i}+a_{3} D_{3, i}+a_{4} D_{4, i}+u_{t, i}
\end{aligned}
$$

where $i$ is individual $i, t=1, \cdots, 8$ ( 4 year before graduation and 4 years after), $D_{2}$ $=1$ for secondary school graduates, $D_{3}=1$ for first degree holders, and $D_{4}=1$ for Master's holders, $W$ is the annual income from main work in constant 2010 prices, $X$ are the years of working experience, $S$ is a dummy variable for sex, $D O M$ denotes family status, $S L M$ the current state of the respondent in the labour market, $M$ the degree mark (secondary level or Bachelor's or Master's), $M A T C H$ the relevance of the job to the degree (mismatching), $O Q$ is a dummy to account for overqualification, $S E C$ is the sector of employment, TRUN accounts for an active participation in trade unions, $L A N G$ is the knowledge of a foreign language ( $x x=1$ for English, 2 for French, 3 for German and 4 for any other foreign language), COMP is computer skills (Word, Excel, PowerPoint, database management, use of Internet, accounting packages and other specialised software) and $u_{t, i}$ is the disturbance term or error term that is assumed to be a random variable representing all the variables that affect the logarithm of wages and were not taken into account in (4).

\subsection{Data Description}

The data for the variables in (4) was extracted from the questionnaires collected for a Hellenic Open University (HOU) research project co-financed by the European Union (European Social Fund, ESF) and Greek national funds through ${ }^{2}$ Please see the "Data description" section below. 
the Operational Program "Education and Lifelong Learning" of the National Strategic Reference Framework (NSRF). The survey period was from June to October 2015.

The questionnaire was stratified into five different categories of individuals:

1) HOU first degree graduates; 712 questionnaires were completed from this category.

2) First degree graduates of traditional Universities; 120 questionnaires were completed from this category.

3) Applied for a HOU degree but not selected, secondary education graduates; 734 were completed from this category. The selection of students, both undergraduate and graduate is done at HOU by lottery.

4) Master's degree HOU graduates; 345 were completed from this category.

5) Traditional Universities Master's graduates; 201 were completed from this category.

The total number of questionnaires collected by the survey was 2112 . Each individual was asked to report remuneration and employment data for a total of eight years, of which four years were before graduation and four years after. Therefore, the original sample size consisted of 16,896 observations.

\subsection{Methodology for Estimating the Returns to Investment for HOU and Traditional University Graduates}

For the estimation of the returns to investment for the HOU first degree and Master's graduates and the graduates from traditional universities Equation (4) was estimated separately using the sample data for HOU graduates and the traditional universities graduates. Category C "Applied for a HOU degree but not selected secondary education graduates" was included in both samples for control purposes.

The objective was to find estimates for the coefficients of $D_{2}, D_{3}$ and $D_{4}$ and then calculate the rates of return between levels of education for HOU graduates and traditional university graduates using (3). A problem arises with the estimation of the coefficient of the $D_{2}$ variable. The variable cannot be included in the estimated equation because it will cause perfect multicollinearity. In fact the same applies for each of the dummy variables categories included in (4) and one variable from each category has to be excluded. When estimating (4) the coefficients of the excluded dummies are included in the intercept. If the Mincer equitation was to be estimated in its simple form, as in (2), the coefficient of the $D_{1}$ variable, $\alpha_{1}$, could had been calculated as $\hat{\alpha}_{1}=\hat{\beta}_{0}-\hat{\alpha}_{2}-\hat{\alpha}_{3}-\hat{\alpha}_{4}$. However, the same technique cannot be used when estimating (4) because the coefficients of all the excluded dummies would be included into the intercept.

To circumvent this problem (4) was estimated in two stages: first it was estimated without the $D_{2}, D_{3}$ and $D_{4}$ dummies. Therefore, the effects of education on wages were left in the residuals. Then the latter were saved and they were used as a regressant in the following regression, with regressors the dummy variables representing the levels of education. Again, to avoid multicollinearity one 
of the dummies (in our case $D_{2}$ ) has to be excluded from the estimation:

$$
\hat{u}_{t, i}=\beta_{0}+a_{3} D_{3}+a_{4} D_{4}+v_{t, i}
$$

therefore, the $\alpha_{2}$ coefficient of $D_{2}$ can be calculated as:

$$
\hat{\alpha}_{2}=\hat{\beta}_{0}-\hat{\alpha}_{3}-\hat{\alpha}_{4}
$$

Following (3) the returns to investment for undergraduate (UNDER) and postgraduate (POST) studies can be calculated as:

$$
R^{\mathrm{UNDER}}=\frac{\hat{\alpha}_{3}-\hat{\alpha}_{2}}{4}, R^{\mathrm{POST}}=\hat{a}_{4}-\hat{a}_{3}
$$

After the estimation of (4) and (5) using the two samples i.e. the sample for the HOU graduates and the sample for the traditional university graduates, (7) can be calculated for each of these two categories ${ }^{3}$ and the difference in the returns between the two categories of graduates can be tested using a Wald type test as follows:

$$
\begin{aligned}
& H_{0}: R^{\text {UNDER_HOU }}=R^{\text {UNDER_TRADITIONAL }}, \\
& H_{1}: R^{\text {UNDER_HOU }} \neq R^{\text {UNDER_TRADITIONAL }} \\
& H_{0}: R^{\text {UNDER_HOU }}=R^{\text {UNDER_TRADITIONAL }}, \\
& H_{1}: R^{\text {UNDER_HOU }} \neq R^{\text {UNDER_TRADITIONAL }}
\end{aligned}
$$

where the superscripts UNDER, POST, HOU and TRADITIONAL denote first degree graduates, master's graduates, Hellenic Open University and traditional universities, respectively.

By substituting (6) and (7) into (8) and (9) the two hypotheses can be tested using a Wald test for:

$$
\begin{gathered}
H_{0}: a_{3}^{H}=\frac{2 a_{3}^{T}+a_{4}^{T}+\beta_{0}^{H}-\beta_{0}^{T}-a_{4}^{H}}{2}, \\
H_{1}: a_{3}^{H} \neq \frac{2 a_{3}^{T}+a_{4}^{T}+\beta_{0}^{H}-\beta_{0}^{T}-a_{4}^{H}}{2} \\
H_{0}: a_{4}^{H}=a_{3}^{H}+a_{4}^{T}-a_{3}^{T}, H_{1}: a_{4}^{H} \neq a_{3}^{H}+a_{4}^{T}-a_{3}^{T}
\end{gathered}
$$

where the superscripts $H$ and $T$ indicate that the coefficient is from the regression with the HOU and traditional universities sample, respectively.

If the null hypothesis in (10) is rejected at least 0.05 level of statistical significance then it will be concluded that the difference in the rates of return for the first degree studies between HOU and traditional universities is different. Further, if the null hypothesis in (11) is rejected at least 0.05 level of statistical significance then it will be concluded that the difference in the rates of return for the master's between HOU and traditional universities is different.

\subsection{Estimation Method}

It is obvious that (4) has to be estimated with panel data because it concerns with

${ }^{3}$ Due to missing questionnaire data, the actual sample size used for HOU graduates (categories A, C and D) was 8351 observations and for the traditional universities graduates (categories B, C and E) was 4713 observations. 
graduates (subscript $i$ ) and for each graduate we have 8 observations for different consecutive years -four before graduation and four after (subscript $t$ ).

There are different methods for estimating panel data models: 1) with fixed effects (FE), 2) with random effects (RE) and 3) with neither fixed nor random effects.

The FE method is used when the interest is only for the analysis of the effects of variables that change over time. $\mathrm{FE}$ are investigating the relationship between the dependent and independent variables in an entity (country, person, company, etc.). Each entity has its own unique style that may or may not affect the variables that explain the behaviour of the dependent variable. When FE are used it is assumed that something in the person/entity can affect or create bias in the dependent variable that is not included in the independent variables and should be taken into account. The use of FE removes the effect of time-invariant characteristics within each cross-section entity so that the impact of the independent variables on the dependent can be estimated. Another important assumption of the FE model is that each cross-section characteristics that are time invariant (but may be different between the cross-sections) are unique to the individual/entity and should not be associated with other cross-sections. Thus, it is considered that each person/cross-section is different, and therefore the error term and the constant term which includes the individual characteristics, should not be correlated between individuals/cross sections. If the error terms are correlated, then the use of FE is not appropriate (the confidence intervals of the estimated coefficients would not be correct) and another method should be used, that of the random effects (RE). The choice between the two methods is made using the Hausman test.

$$
\begin{aligned}
\ln W_{t, i}= & b_{0}+b_{1} X_{t, i}+b_{2} X_{t, i}^{2}+b S_{i}+\sum_{e=1}^{4} \delta_{e} D O M_{e, i}+\sum_{j=1}^{7} f_{j} S L M_{j, i}+m M_{i} \\
& +\sum_{n=1}^{4} r_{n} M A T C H_{n, i}+\sum_{w=1}^{3} q_{w} O Q_{w, i}+\sum_{s s=1}^{20} s_{s s} S E C_{s s, i}+t u T R U N_{i} \\
& +\sum_{x x=1}^{4} \sum_{f e=1}^{4} f l_{x x, f e} L A N G \_x x_{f e, i}+\sum_{x=1}^{7} y_{x} C O M P_{x, i}+\sum_{i=2}^{n} a_{i} \Phi_{i}+u_{t, i}
\end{aligned}
$$

In the case of FE, (4) is modified as in $(12)^{4}$, where $\Phi_{i}$ are $n-1$ dummy variables and $n$ is the total number of questionnaires. Each of these dummies absorbs the effects on the dependent variable that are specific to each individual. So, the heterogeneity among persons that has not been modelled into (4) is taken into account.

Unlike the fixed effects models (FE) the random effects models (RE) assume that the variation between individuals is random and uncorrelated with the independent variables included in the model. Thus, the distinction between FE and RE model is whether or not the non-observed effects on the dependent variable for each person contain and effects that are correlated across individuals. ${ }^{4}$ Note that the $D_{2}, D_{3}$ and $D_{4}$ variables were removed from (4) and included in (5) for the reasons explained in subsection 3.4. 
Therefore, if we consider that there are differences among individuals that affect the dependent variable then RA models have to be used.

In the case of RE (4) is modified as in (13):

$$
\begin{aligned}
\ln W_{t, i}= & b_{0}+b_{1} X_{t, i}+b_{2} X_{t, i}^{2}+b S_{i}+\sum_{e=1}^{4} \delta_{e} D O M_{e, i}+\sum_{j=1}^{7} f_{j} S L M_{j, i}+m M_{i} \\
& +\sum_{n=1}^{4} r_{n} M A T C H_{n, i}+\sum_{w=1}^{3} q_{w} O Q_{w, i}+\sum_{s s=1}^{20} s_{s s} S E C_{s s, i}+t u T R U N_{i} \\
& +\sum_{x x=1}^{4} \sum_{f e=1}^{4} f l_{x x, f e} L A N G \_x x_{f e, i}+\sum_{x=1}^{7} y_{x} C O M P_{x, i}+e_{t, i}+u_{t, i}
\end{aligned}
$$

where $e_{t, i}$ is the disturbance term within each individual ( $i$ is each cross-section) and $u_{t, i}$ is the disturbance term across individuals.

To determine which estimation method has to be used (Equation (12) or (13)) the Hausman test has been used where the null hypothesis is that the model has $\mathrm{RE}$ while the alternative is that it has FE. If the Hausman test shows that the RE model has to be used (Equation (13)) we can perform a further test to examine if we can use OLS instead of RE. This test is an LM test (Langrange Multiplier test). The null hypothesis is that the variances between the cross sections are zero. If we could not reject the null hypothesis then we would conclude that the use of the RE estimation method is not appropriate and OLS should be used.

The chi-square statistic from the Hausman test when (4) is estimated using the sample for HOU graduates was 79.41 and it was statistically significant at 0.00 level of significance while when it was estimated using the traditional universities sample it had a value of 10,939 and it was also statistically significant at 0.00 level of significance. Therefore, it is concluded that the null hypothesis should be rejected and (4) should be estimated using the FE model (described by (12), above) for both datasets (HOU/traditional Universities).

\section{Results}

The estimation results from the estimation of (12) using the HOU and the traditional universities graduates sample is presented in Appendix A and B, respectively. From the values and signs of the coefficients of the variables that affect wages for HOU and traditional university graduates the following can be observed: 1) women are paid lower wages than men in the labour market, 2) the coefficient of the degree mark (secondary level, Bachelor's or Master's) is not a statistically significant, 3) the coefficient of the relevance of the job to the degree is statistically significant, 4) the coefficient of overqualification is not statistically significant, 5) some sectors are paying more and some other less: electric power production, water supply, construction, wholesale, transportation and storage, communication and publishing, financial activities are paying more than average while real estate management and domestic activities are paying less, 6) the coefficient of the English and French language skills at any level of knowledge are not statistically significant; only the coefficient of the knowledge of the German language at an advanced level has an impact on wages. Finally, it can be observed 
that the coefficients of computer skills are not statistically significant.

As explained in Section 3 ("Methodology"), in order to estimate the coefficients of the dummy variables for each level of education, after the estimation of the modified Mincer equation the residuals were saved and they have been used as a regressant with the regressors being the dummy variables for each level of education (Equation (5)). The results from these regressions are presented in Table 2 below.

Then the returns to education for HOU and traditional universities can be calculated using (7), above. These are presented in columns four and five in Table 3 below. Columns four and five present the returns to education investment for undergraduate and master's studies, respectively, in HOU and in traditional universities.

Table 2. Estimation results on the returns to education for HOU and traditional universities graduates.

\begin{tabular}{cccc}
\hline & Hellenic Open University graduates & \\
\hline Number of obs & & 8351 & \\
F-statistic & Coefficient & Standard error & $p$-value \\
Variables & 0.386 & 0.022 & 0.000 \\
$D_{3}$ & 0.529 & 0.028 & 0.000 \\
$D_{4}$ & -0.167 & 0.014 & 0.000 \\
Constant & Traditional universities graduates & \\
& & 4719 & \\
Number of obs & & $5.23^{* *}$ & p-value \\
F-statistic & Coefficient & Standard error & 0.079 \\
Variables & 0.073 & 0.041 & 0.003 \\
$D_{3}$ & 0.141 & 0.048 & 0.137 \\
$D_{4}$ & -0.026 & 0.017 & \\
Constant & &
\end{tabular}

Source: Authors' estimates. Notes: The results shown are from the estimation of (5) using the sample for HOU graduates and the sample from traditional universities graduates; the dependent variable is the residuals from the estimation of (12). Two stars indicate statistical significance at less than $1 \%$ level of significance.

Table 3. The returns to years of study for HOU and traditional universities graduates for first degree and master's studies.

\begin{tabular}{|c|c|c|c|c|}
\hline & & & First degree & Master's degree \\
\hline \multicolumn{5}{|c|}{ Hellenic Open University graduates } \\
\hline$\alpha_{2}^{H}$ & $\alpha_{3}^{H}$ & $\alpha_{4}^{H}$ & $R^{\mathrm{UNDER} \_\mathrm{HOU}}$ & $R^{\text {POST_HOU }}$ \\
\hline-1.082 & 0.386 & 0.529 & 0.367 & 0.144 \\
\hline \multicolumn{5}{|c|}{ Traditional universities graduates } \\
\hline$\alpha_{2}^{T}$ & $\alpha_{3}^{T}$ & $\alpha_{4}^{T}$ & $R^{\text {UNDER_TRADITIONAL }}$ & $R^{\text {POST_TRADITIONAL }}$ \\
\hline-0.239 & 0.073 & 0.141 & 0.078 & 0.068 \\
\hline
\end{tabular}

Source: Authors' calculations, Table 2 and (6), (7). Notes: The first column was calculated from (6) while four and five were calculated from (7). Column four shows the returns for each year of study in HOU and in traditional universities while column five shows the total returns for the master's degree awarded by HOU and by traditional universities. 
Table 3 shows that the returns of university education are higher in case of graduates holding Bachelor's degree than those with Master's degree, a result verified by literature see e.g. Liwinski (2016).

Our results are in line with previous studies in Greece, see among others e.g. Kanellopoulos and Cholezas (2014), showing that returns to education for postgraduate studies are significantly higher than the rates of return of the first degree and, also, that the he rates of return for higher education are high even after the 2008 sovereign debt crisis. We observe that the returns to investment for studies in HOU are significantly higher than that of traditional universities graduates (approximately four times higher). The same applies to the returns for studies in the HOU master's degree relative to those from traditional universities. The return to investment in $\mathrm{HOU}$ is about twice that of the traditional universities.

To draw conclusions from these results a final test should be made: the statistical significance in the difference of returns for undergraduate and postgraduate studies between HOU graduates and the graduates from traditional university should be tested. Therefore, to test hypotheses (8) and (9), presented in subsection 3.4 above, the Wald test has been used, as described by (10) and (11).

The F-statistic for (10) had a value of 284.52 and it was statistically significant at 0.000 level of statistical significance while the F-statistic for (11) had a value of 6.25 and it was statistically significant at 0.012 level of statistical significance. Therefore, for both (10) and (11) the null hypothesis is rejected and the alternative is adopted ${ }^{5}$. Consequently, for both first and master's degree holders there is a difference in the returns to investment (in schooling years) between the Distance Learning and Traditional Universities in Greece.

\section{Conclusions and Policy Implications}

In this paper, we extend the literature on the rate of returns to Investment in Higher Education towards studies in distance learning Universities. To this aim, we first, develop a methodology for measuring the return to investment in education for both undergraduate and graduate studies. Second, we explore the difference in returns between, on one hand, graduates of the distance learning university (the Hellenic Open University, HOU) and on the other hand, graduates from two traditional universities, in Greece. The returns to investment in education were estimated using a modified form of the Mincer equation. The data used was extracted from questionnaires collected with field research performed within the framework of a HOU research project. A methodology was also developed for testing the statistical significance of the difference in the returns to education for HOU and traditional universities graduates using a Wald test.

We proceed our analysis by first estimating a modified Mincer equation and our findings show, first, that women are paid lower wages than men in the la-

${ }^{5}$ That is, the alternative hypothesis is adopted with zero margin of error in the case of undergraduate studies while the error possibility for postgraduate studies is $1.2 \%$ which is far below the acceptable statistical error of $5 \%$ (significance level) that is normally used. 
bour market, a result confirmed by some previous studies though some other studies support quite the opposite. Second, the relevance of the job to the degree of studies is statistically significant. This is a rather innovative result not explored by other studies.

Next, we turn our analysis into finding the rate of return to investment in education. We found that the rate of return to investment in education for HOU graduates is four time higher than that of the traditional Universities for the first degree graduates and about double for the Master's degree graduates. This result can be explained because HOU graduates are at a more mature stage in their carriers when they are getting their degree while most of the traditional University graduates are at a very early stage as they are just entering the labour market.

Finally, we test for the statistical significance in the difference of returns for undergraduate and postgraduate studies between HOU graduates and the graduates from traditional university by using the Wald test. This test shows that the difference of returns between HOU graduates and the other graduates is indeed statistically significant.

From policy perspective, our results are interesting for the Ministry of education that is responsible for the educational policy of higher education in Greece and also for the HOU administration authorities. This is so, because our findings suggest that a distance learning University may not only be considered as a second chance to education for mature students often facing time and budget restrictions, but, it may also be seen as a worthwhile investment enabling much higher private returns compared to the alternative route, i.e. following studies in traditional universities. Therefore, distance learning universities may be used by policy authorities as a vehicle to reduce income inequalities and increasing social mobility.

\section{Financial}

This research was carried out as a research project co-financed by the European Union (European Social Fund, ESF) and Greek national funds through the Operational Program "Education and Lifelong Learning" of the National Strategic Reference Framework (NSRF). Financial support is gratefully acknowledged.

\section{Conflicts of Interest}

The authors declare no conflicts of interest regarding the publication of this paper.

\section{References}

Becker, G. S. (1964). Human Capital: A Theoretical and Empirical Analysis with Special Reference to Education (3rd Edition). Chicago: The University of Chicago Press.

Bunzel, H., Christensen, B., Neumann, G., \& Robin, J. (2008). Structural Models of Wage and Employment Dynamics (Volume 275). Amsterdam: Elsevier.

D’Aguiar, S., \& Harrison, N. (2016). Returning from Earning: UK Graduates Returning to 
Postgraduate Study, with Particular Respect to STEM Subjects, Gender and Ethnicity. Journal of Education and Work, 29, 584-613.

https://doi.org/10.1080/13639080.2014.1001332

Goodman, J., Melkers, J., \& Pallais, A. (2016). Can Online Delivery Increase Access to Education? Working Paper 22754, National Bureau of Economic Research. http://www.nber.org/papers/w22754

Harmon, C. (2011). Economic Returns to Education: What We Know, What We Don't Know, and Where We Are Going-Some Brief Pointers. IZA Policy Paper No. 29.

Heinrich, G., \& Hildebrand, V. (2005). Returns to Education in the European Union: A Reassessment from Comparative Data. European Journal of Education, 40, No. 1.

Kanellopoulos, C. N. (1997). Public-Private Wage Differentials in Greece. Applied Economics, 29, 1023-1032. https://doi.org/10.1080/000368497326417

Kanellopoulos, N., Mitrakos, T., Tsaklogloy, P., \& Cholezas, I. (2013). The Effects of the Current Crisis on Private Returns to Education in Greece. Oikonomiko Deltio, 2013, 35-67.

Kanellopoulos, N., \& Cholezas, I. (2014). Private Returns to Education in Greece: The Effects of Recession. Athens: Institute of Labor.

Lambropoulos, H., \& Psacharopoulos, G. (1992). Educational Expansion and Earnings Differentials in Greece. Comparative Educational Review, 36, 52-70.

https://doi.org/10.1086/447081

Leibenstein, H. (1967). Rates of Return to Education in Greece. Economic Development Report, No. 94, Harvard University.

Livanos, I., \& Pouliakas, K. (2011). Wage Returns to University Disciplines in Greece: Are Greek Higher Education Degrees Trojan Horses? Education Economics, 19, 411-445. https://doi.org/10.1080/09645290903546363

Liwinski, J. (2016). Does It Pay to Study Abroad? Evidence from Poland. In 6th Economics \& Finance Conference (Working Papers 25/2016). Paris: OECD Headquarters and University of Warsaw.

Magoula, T., \& Psacharopoulos, G. (1999). Schooling and Monetary Rewards in Greece: An Over-Education False Alarm? Applied Economics, 31, 1589-1597. https://doi.org/10.1080/000368499323111

Mincer, J. (1958). Investments in Human Capital and Personal Income Distribution. Journal of Political Economy, 66, 281-302. https://doi.org/10.1086/258055

Mitrakos, T., Tsaklogloy, P., \& Cholezas, I. (2010). Factors Determining Wages in Greece with Emphasis on Wages of University Graduates. Oikonomiko Deltio, 2010, 7-39. (In Greek)

Naylor, R., Smith, J., \& Telhaj, S. (2015). Graduate Returns, Degree Class Premia and Higher Education Expansion in the UK. CEP Discussion Paper No. 1392.

Oreopoulos, P., \& Petronijevic, U. (2013). Making College Worth It: A Review of Research on the Returns to Higher Education. NBER Working Paper No. 19053.

Patrinos, H. A. (1995). Socioeconomic Background, Schooling, Experience, Ability and Monetary Rewards in Greece. Economics of Education Review, 14, 85-91. https://doi.org/10.1016/0272-7757(94)00028-5

Prodromidis, K., \& Prodromidis, P. (2008). Returns to Education: The Greek Experience, 1998-1999. Applied Economics, 40, 1023-1030. https://doi.org/10.1080/00036840600771197

Psacharopoulos, G. (2012). The Value of Investment in Education: Theory, Evidence, and Policy. Journal of Education Finance, 32, 113-136. 
http://www.jstor.org/stable/40704288

Psacharopoulos, G. (1982). Earnings and Education in Greece, 1960-1977. European Economic Review, 17, 333-347. https://doi.org/10.1016/S0014-2921(82)80068-8

Psacharopoulos, G., \& Patrinos (2004). Human Capital and Rates of Return. In G. Johnes, \& J. Johnes (Eds.), International Handbook on the Economics of Education (Chapter 1, pp. 1-57). Cheltenham: Edward Elgar Publishing. https://doi.org/10.4337/9781845421694.00006

Schultz, T. W. (1961). Investment in Human Capital. American Economic Review, 51, 1-17.

Tsakloglou, P., \& Cholezas, I. (2001). “Greece” in Education and Earnings in Europe. 
Appendix A: Estimation Results of the Modified Mincer Equation (Equation (12)) Using the Sample for HOU Graduates

\begin{tabular}{|c|c|}
\hline variable & Coefficient \\
\hline $\mathrm{x}$ & $0.02999561^{\star * \star}$ \\
\hline$x \_2$ & $-0.00060326^{\star * *}$ \\
\hline s & $-0.09408224^{* * *}$ \\
\hline dom_1 & $0.20651187^{\star * *}$ \\
\hline dom $\_2$ & $0.21138365^{\star * \star}$ \\
\hline dom_3 & $0.25847454^{\star \star \star}$ \\
\hline slm_1 & 0.07714503 \\
\hline slm_2 & $-0.29886473^{\star *}$ \\
\hline slm_3 & $-0.54874309^{\star * *}$ \\
\hline slm_ 4 & $-0.65052923^{\star * *}$ \\
\hline $\operatorname{slm} \_5$ & (omitted) \\
\hline slm_6 & (omitted) \\
\hline $\mathrm{m}$ & 0.00386604 \\
\hline match_1 & $0.22671737^{\star * *}$ \\
\hline match_2 & $0.1950426^{\star * \star}$ \\
\hline match_3 & $0.09697944^{*}$ \\
\hline oq_1 & 0.02586373 \\
\hline oq_2 & -0.00934277 \\
\hline sec_k_1 & -0.01505538 \\
\hline sec_k $\_2$ & -0.35591925 \\
\hline sec_k_3 & 0.03515527 \\
\hline sec_k_ $\_4$ & $0.1706785^{\star}$ \\
\hline sec_k_5 & $0.1874512127^{* * *}$ \\
\hline sec_k_6 & $0.28157245^{\star * *}$ \\
\hline sec_k_7 & $0.13973724^{\star * \star}$ \\
\hline sec_k_8 & $0.41636845^{\star * *}$ \\
\hline sec_k_9 & 0.05267706 \\
\hline sec_k_10 & $0.18554717^{\star * *}$ \\
\hline sec_k_11 & $0.37127245^{\prime \prime}$ \\
\hline
\end{tabular}




\section{Continued}

\begin{tabular}{|c|c|}
\hline sec_k_12 & $-0.6967696^{\star * *}$ \\
\hline sec_k_13 & $0.30998342^{* * *}$ \\
\hline sec_k_14 & 0.02031798 \\
\hline sec_k_15 & $0.190438^{\star * *}$ \\
\hline sec_k_17 & -0.02165325 \\
\hline sec_k_18 & $0.14123129^{*}$ \\
\hline sec_k_19 & $0.10136685^{\star *}$ \\
\hline sec_k_20 & $-1.7232479^{* * *}$ \\
\hline trun & 0.0032762 \\
\hline lang_eng_1 & -0.04760707 \\
\hline lang_eng_2 & -0.05459158 \\
\hline lang_eng_3 & 0.00299931 \\
\hline lang_fr_1 & $0.0892474^{*}$ \\
\hline lang_fr_2 & 0.10485228 \\
\hline lang_fr_3 & -0.02886038 \\
\hline lang_ger_1 & $0.24551919^{* * *}$ \\
\hline lang_ger_2 & -0.0760187 \\
\hline lang_ger_3 & 0.00595632 \\
\hline lang_other_1 & -0.05128273 \\
\hline lang_other_2 & 0.03380335 \\
\hline lang_other_3 & $-0.14048097^{\star * *}$ \\
\hline comp_acc & -0.02813504 \\
\hline comp_db & 0.06063406 \\
\hline comp_excel & -0.02621227 \\
\hline comp_int & 0.0509363 \\
\hline comp_other & $-0.09068124^{\star *}$ \\
\hline comp_pp & $0.09496735^{*}$ \\
\hline comp_word & -0.08952656 \\
\hline _cons & $8.7812058^{\star * *}$ \\
\hline $\mathrm{N}$ & 8351 \\
\hline
\end{tabular}

Legend: ${ }^{\star} p<0.05 ;{ }^{* *} p<0.01 ;{ }^{* *} p<0.001$. 
Appendix B: Estimation Results of the Modified Mincer Equation (Equation (12)) Using the Sample for Traditional Universities Graduates

\begin{tabular}{|c|c|}
\hline variable & Coefficient \\
\hline $\mathrm{x}$ & $0.04728222^{* * *}$ \\
\hline$x \_2$ & $-0.00150402^{\star * *}$ \\
\hline $\mathrm{s}$ & $-0.09931532^{\star * *}$ \\
\hline dom_1 & $0.24106918^{\star * *}$ \\
\hline dom_2 & $0.31860914^{\star * *}$ \\
\hline dom_3 & 0.11494393 \\
\hline slm_1 & $-0.86162689^{* * *}$ \\
\hline $\operatorname{slm} \_2$ & $-1.1618132^{* * *}$ \\
\hline slm_3 & $-1.5351031^{\star * *}$ \\
\hline slm_4 & $-1.5913845^{\star * *}$ \\
\hline slm_5 & (omitted) \\
\hline slm_6 & (omitted) \\
\hline $\mathrm{m}$ & $0.01467896^{*}$ \\
\hline match_1 & $0.15509084^{*}$ \\
\hline match_2 & 0.0310158 \\
\hline match_3 & $-0.27449302^{\star *}$ \\
\hline oq_1 & 0.03813167 \\
\hline oq_2 & 0.00858196 \\
\hline sec_k_1 & -0.02815242 \\
\hline sec $\_k \_2$ & $-0.84302853^{* *}$ \\
\hline sec_k_3 & $0.219024388^{* *}$ \\
\hline sec_k_k 4 & 0.14151339 \\
\hline sec_k_5 & $0.52243945^{* * *}$ \\
\hline sec_k_6 & $0.504165417^{* * *}$ \\
\hline sec_k_7 & $0.32148318^{\star * *}$ \\
\hline sec_k $\_8$ & $0.48071748^{* * *}$ \\
\hline sec_k_9 & -0.05698125 \\
\hline sec_k_10 & 0.0020605 \\
\hline sec_k_11 & $0.48953824^{* * *}$ \\
\hline
\end{tabular}




\section{Continued}

\begin{tabular}{|c|c|}
\hline sec_k_12 & $-0.37816911^{* * *}$ \\
\hline sec_k_13 & $0.36034449^{* * *}$ \\
\hline sec_k_14 & 0.00903681 \\
\hline sec_k_15 & $0.28240242^{* * *}$ \\
\hline sec_k_17 & 0.1422683 \\
\hline sec_k_18 & $0.34252151^{* * *}$ \\
\hline sec_k_19 & 0.10416805 \\
\hline sec_k_20 & $-1.4031909^{* * *}$ \\
\hline trun & $0.2117436^{* * *}$ \\
\hline lang_eng_1 & -0.00139581 \\
\hline lang_eng_2 & -0.01503238 \\
\hline lang_eng_3 & -0.02631356 \\
\hline lang_fr_1 & $0.2513515^{\star \star \star}$ \\
\hline lang_fr_2 & $0.27958678^{\star *}$ \\
\hline lang_fr_3 & -0.04051103 \\
\hline lang_ger_1 & $0.21337395^{\star * *}$ \\
\hline lang_ger_2 & 0.02369367 \\
\hline lang_ger_3 & $0.1408814^{*}$ \\
\hline lang_other_1 & -0.03130851 \\
\hline lang_other_2 & 0.11069383 \\
\hline lang_other_3 & $-0.16043191^{*}$ \\
\hline comp_acc & $-0.10610846^{*}$ \\
\hline comp_db & -0.01379947 \\
\hline comp_excel & -0.15873376 \\
\hline comp_int & 0.01170323 \\
\hline comp_other & -0.02114559 \\
\hline comp_pp & $0.16097301^{*}$ \\
\hline comp_word & -0.0413102 \\
\hline _cons & $9.3519785^{\star * *}$ \\
\hline $\mathrm{N}$ & 4713 \\
\hline
\end{tabular}

Legend: ${ }^{*} p<0.05 ;{ }^{* *} p<0.01 ;{ }^{* * *} p<0.001$. 